\title{
The Relationships between Lecture Attendance or Accessing Lecture Recordings and Academic Outcomes: Results from a Pharmacology Course in a Biomedical Science Degree
}

\author{
Sheila A. Doggrell ${ }^{\mathrm{a}}$ \\ Corresponding author: Sheila Doggrell (sheila.doggrell@qut.edu.au) \\ ${ }^{a}$ Faculty of Health, Queensland University of Technology, Brisbane, QLD 4002, Australia
}

Keywords: lecture attendance, lecture recordings, academic outcomes, pharmacology

\begin{abstract}
The effect of lecture recordings on academic outcomes is not clear, and it is not known whether lecture recordings alter the association between attending lectures and academic outcomes. In a third-year pharmacology course, 39 of 42 students consented to the study. Sixty percent of the students attended the first lecture monitored, and then lecture attendance declined to an average of $41 \% /$ lecture. The final marks were significantly higher for students who attended $\geq 50 \%$ than those who attended $<50 \%$ of lectures. There was a weak positive association between lecture attendance and the final course mark in pharmacology. Thirteen of the 39 students did not access any lecture recordings, and an additional 10 students did not access any lecture recordings to $\geq 60 \%$ completion. For the 26 students who accessed the lecture recordings, there was a weak negative association between number of lectures accessed to $\geq 80 \%$ completion and final mark, but no correlation when the one student who failed the course was removed from the analysis. From this study, it does not seem that lecture recordings can be used as an effective replacement of face-to-face lectures. As lecture recordings were accessed more by the students who subsequently had poorer outcomes, it is possible that they would have had even poorer outcomes without this access.
\end{abstract}

\section{Introduction}

There are many factors that predict academic performance at university. These include academic predictors, psychosocial predictors, cognitive, and demographics (reviewed in McKenzie \& Schwitzer, 2001). In addition, for many years, especially before the introduction of technology into teaching, it was assumed by most teachers, that academic performance was related to class attendance with students who attended classes more frequently obtaining better grades. For college students in the US, a major meta-analysis of 68 studies published $\leq 2009$ showed that there was a strong relationship between attendance and grades, and this was also confirmed for the subgroup of 11 studies of students studying science. This study also showed that attendance was a better predictor of grade than any other known predictors of academic performance including entry scores, study habits and study skills (Credé, Roch, \& Kieszczynka, 2010).

No information on the availability of lecture recordings is given in the meta-analysis of Credé et al., (2010), and thus it is not clear whether this availability changes the relationship between lecture attendance and academic outcomes. Forty of the 68 studies combined in this metaanalysis were before or in 2000 and probably do not relate to the current teaching/lecture recording environment. The increasing use of technology, especially the availability of lecture recordings, may reduce lecture attendance (Traphagen, Kucsera, \& Kyoko, 2010). With the 
use of lecture recordings, it is possible that students who have low lecture attendance may have improved performance, compared to those with low attendance who do not use lecture recordings. The first aim of this study was to determine the relationship between lecture attendance and academic outcomes for students who had access to lecture recordings.

Lecture recordings are the backbone of distance learning, but access to these for students who have face-to-face lectures is relatively new. For those who have access to face-to-face lectures, studies of any association between the use of lecture recordings and academic outcomes have given mixed results. Thus, two studies have shown that course grade was higher for those that viewed more online lectures (law students, Wieling \& Hofman, 2010; nursing students studying anatomy and physiology, Guy, Byrne, \& Dobos, 2018). One study has shown that the use of lecture recordings, by medical science students, does not have any effect on exam grades (Leadbeater, Shuttleworth, Couperthewaite, \& Nightingale, 2013). Another study has shown that lecture recordings did not have an impact on outcomes for seven of eight courses being undertaken by medical students but was negatively associated with the academic outcomes in pharmacology (Frankin, Gibson, Samuel, Teeter, \& Clarkson, 2011). In addition, three studies have shown that accessing lecture recordings is negatively associated with academic performance (medical students, McNulty, Hoyt, Gruener, Chandrasekhar, Espiritu, Price, \& Neheedy, 2009; students studying microeconomic principles, Williams, Birch, \& Hancock, 2012, nursing students studying anatomy and physiology; Johnston, Massa, \& Burne, 2013). The second aim of this study was to determine the relationship between accessing lecture recordings and academic outcomes for students in a pharmacology course in a biomedical science degree.

\section{Methods}

At the Queensland University of Technology (QUT), a pharmacology course is taught as part of the Biomedical Science degree. It is a third-year level, elective, 12 credit point unit (96 credits/year is full-time study). The course had three hours of lecturing/week, over 11 weeks, which were made available via Blackboard as recordings (Echo 360; voice and Powerpoint slides). The course was supported by two hours of computer-based tutorial/week. In 2017, the marks were $60 \%$ for the examination and $40 \%$ for an assignment. The examinations were midsemester (25\%) and final (35\%) and both had multiple choice questions and short answer questions. The assignment was not related to lecture content.

Ethics approval for this study was obtained from the Human Research Ethics Committee at QUT; Ethics Approval Number 1700000690. During the computer-based tutorial in week 1, consent was sought from the students by the author to undertake the study. The author was not involved in any aspect of the running or teaching of the pharmacology course. A list of students who had consented to participate was prepared, and circulated at the lectures from week 2 onwards, for attending students to sign. From the signed list, the percentage of attending students/week was determined and averaged, and for each participant, the number of lectures attended was collated. The participating students were divided into those that attended $<50 \%$ or $\geq 50 \%$ of the lectures (where signatures were collected), and for both groups the average attendance was determined.

Grades for participating students were collated and averaged. Passing grades at QUT are 4 (overall mark, 50-64\%), 5 (65-74\%), 6 (75-84\%) and 7 ( $\geq 85 \%)$. The other academic outcomes measured were the overall mark, marks for both examinations, and for the assignment. These marks were calculated as a percentage of $100 \%$ and averaged. The grades and marks for those 
participants attending $<50 \%$ or $\geq 50 \%$ of the lectures were compared. In addition, regression line analysis of marks vs lecture attendance was undertaken.

The lecture recording data provided for individual students from Echo 360 included the number of recording accessed and number of minutes that the recording ran for, but not the time of day/date when the recordings were accessed. For the participating students, access to lecture recordings was divided in two groups; the number of lectures accessed for $\geq 60 \%$ or $\geq 80 \%$ completion. Regression line analysis of marks vs number of lectures accessed was also undertaken for all participating students, and for the students who accessed $\geq 1$ lecture to $\geq$ $60 \%$ or $\geq 80 \%$ completion.

Individual values were compared by Student's unpaired t-test with $\mathrm{P}$ values of less than 0.05 being considered significantly different. Previous studies, using linear regression to determine any association between lecture attendance relates and academic outcomes for biological science students, have determined Pearson's correlation coefficients (Horton, Wilderman \& Saint, 2012; Azab, Sakena, Alghanem, Bidle, Molgaard, Albright, \& Karimbux, 2016; Popovic, Popovic, Dragovic, \& Cmiljanic. 2017). We have used linear regression to determine any association between lecture attendance or accessing lecture regression and academic outcomes and Pearson's correlation coefficients (r) using Microsoft Excel. Correlation coefficients of 0.3 to $<0.5,0.5$ to $<0.7$, and 0.7 to 1 were considered weak, moderate, and strong correlations, respectively.

\section{Results}

At the start of semester, 42 students were enrolled in the pharmacology course. Thirty-nine of these students attended the first computer-based tutorial in the semester, and all consented to participate in the study. Thirty-eight of the participating students passed the course and one failed.

\section{Lecture attendance}

Percentage attendance was not measured in week 1, as this was prior to the consent collecting process, or in week 7 , when the mid-semester exam was undertaken in the time allocated to the lecture. In week 11, there was a revision session in lieu of a lecture. Attendance was highest at start of semester ( $\sim 60 \%$ of participants attended), and then declined to $\sim 10 \%$ in week 10 , before increasing for the revision session (Figure 1).

The average percentage lecture attendance/student was $40.7 \% \pm 5.4 \%$ (39); SEM, $\mathrm{n}=39$. When the students were divided into those that attended $<50 \%$ or $\geq 50 \%$ of the lectures, 22 had attended $<50 \%$ with an average attendance of $14.6 \% \pm 3.5 \%$, and 17 had attended $\geq 50 \%$ of the lectures, with an average of $74.5 \% \pm 3.3 \%$. 


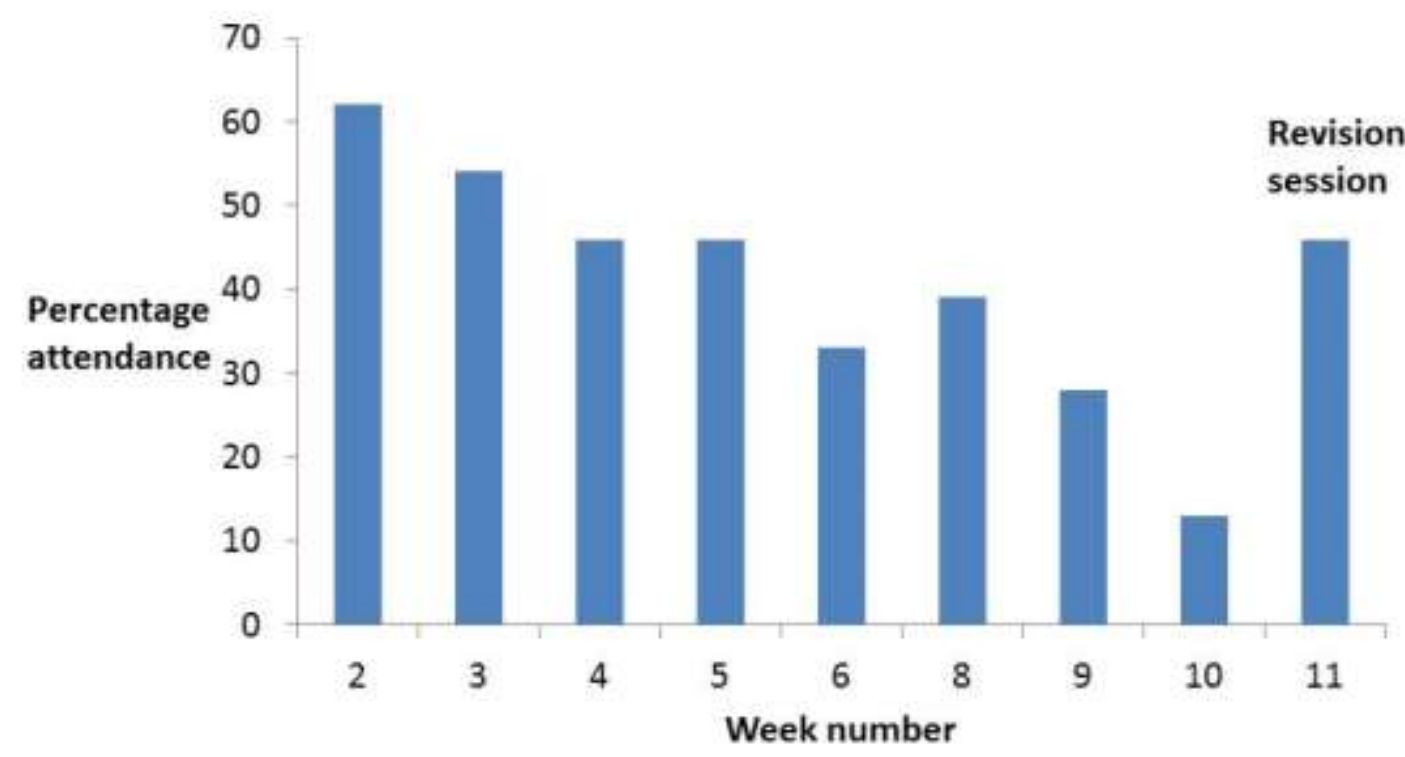

Figure 1: Percentage of students attending the lectures plotted against the week number in semester

\section{Lecture attendance and academic outcomes}

The average grade for all the participating students in the course was $5.9 \pm 0.3$ (39) with the students who attended $\geq 50 \%$ of the lectures achieving a significantly higher grade of $6.5 \pm 0.2$ (17) compared to $5.5 \pm 0.3$ (22) for the students who attended $<50 \%$ of the lectures $(\mathrm{P}=0.020$, by unpaired Student's t-test). The overall average mark for all the participating students from the unit was $79.2 \% \pm 3.8 \%$ (39), and the students who attended $\geq 50 \%$ of the lectures achieving a significantly higher mark than the students who attended $<50 \%$ of the lectures (Table 1 ). The average percentage marks for participating students in the combined examinations, midsemester examination, final examination and assignment were $77.1 \% \pm 4.2 \%, 81.2 \% \pm 4.3 \%$, $74.2 \% \pm 4.6$ and $81.8 \% \pm 3.3(39)$, respectively.

The students who attended $\geq 50 \%$ of the lectures achieved a higher mark than the students who attended $<50 \%$ of the lectures in the mid-semester and final examination. This difference was more pronounced for the final than mid-semester examination due to a reduced performance of the students who attended $<50 \%$ of the lectures in the final examination, and consequently, the difference reached significance for the final, compared to the mid-semester examination (Table 1). Because of the significantly higher mark in the final examination, the combined examination mark was also significantly higher than the students who attended $\geq 50 \%$ of the lectures, compared to $<50 \%$ of the lectures (Table 1). The assignment mark was not significantly different between the students who attended $\geq 50 \%$ and $<50 \%$ of the lectures (Table 1). When the examination (60\% of total) and assignment marks (40\%) were combined, the overall mark was just significantly higher for the students who attended $\geq 50 \%$ versus < $50 \%$ of the lectures (Table 1).

The failing student attended $<50 \%$ of the lectures. Removing this student, from the data analysis for the relationship between lecture attendance and academic outcomes shown in Table 1, did not alter the findings (data not shown). 
Table 1. The relationship between lecture attendance and academic outcomes for students in a pharmacology unit

\begin{tabular}{|l|l|l|l|}
\hline Attendance & $\begin{array}{l}<\mathbf{5 0 \%} \text { of lectures } \\
(\mathbf{n = 2 2})\end{array}$ & $\begin{array}{l}\mathbf{\geq 5 0 \%} \text { of lectures } \\
(\mathbf{n = 1 7 )}\end{array}$ & P value \\
\hline Mid-semester examination & $77.1 \pm 4.5$ & $85.9 \pm 3.9$ & 0.170 \\
\hline Final semester examination & $66.2 \pm 4.6$ & $83.5 \pm 3.8^{*}$ & 0.009 \\
\hline Combined examinations & $70.7 \pm 4.2$ & $84.5 \pm 3.7^{*}$ & 0.025 \\
\hline Assignment & $78.7 \pm 3.6$ & $85.8 \pm 3.0$ & 0.145 \\
\hline Overall mark & $75.0 \pm 3.4$ & $85.2 \pm 3.5^{*}$ & 0.046 \\
\hline
\end{tabular}

Each value is the average percentage \pm SEM

* indicates significantly different, $\mathrm{P}$ values are from Student's unpaired t-test

The $n$ value is the number of students

Regression line analysis was undertaken of grade, overall marks (Figure 2), combined examinations, mid-semester examination, final examination, and assignment against percentage of lecture attendance for all the individual students.

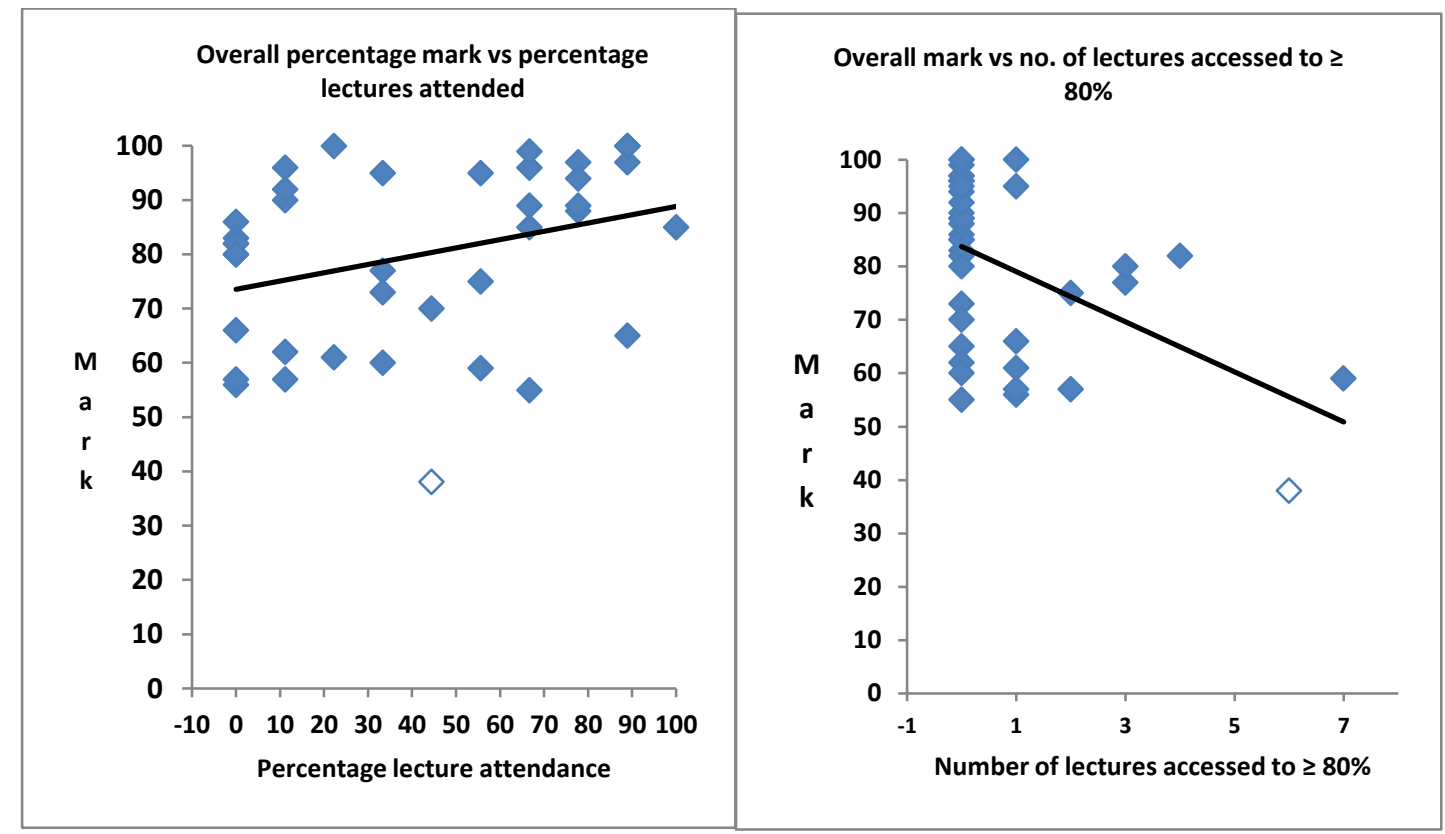

Figure 2. Regression line analysis for relationship between overall marks and percentage of lectures attended (left) or number of lecture recordings accessed to $\geq 80 \%$ (right)

This regression line analysis showed that there was a weak positive correlation with the grade, overall mark, combined examination marks and final examination against attendance, but no correlation with the mid-semester examination or assignment (Table 2).

The most outlying point in the regression line analysis between overall mark and lecture attendance in Figure 2, which is indicated by the unfilled symbol in the figure, belonged to the student who failed the course. Repeating the regression line analysis for the passing students (i.e. removing the data for the failing student) improved the weak correlation between grade, overall mark, combined examination and final examination and lecture attendance (Table 2). The analysis for the passing students only also improved the correlation for the mid-semester examination and attendance making it reach the threshold for a weak correlation (Table 2). The 
lack of a correlation between assignment mark and attendance remained when the failing student was removed from the analysis (Table 2).

Table 2. Pearson's correlation coefficients for grade and marks vs percentage lecture attendance and number of lecture recordings accessed to $\geq 80 \%$

\begin{tabular}{|c|c|c|c|c|c|c|c|}
\hline & \multicolumn{7}{|c|}{ Pearson's correlation coefficients } \\
\hline & Students & Grade & $\begin{array}{l}\text { Overal } \\
\text { I mark }\end{array}$ & $\begin{array}{l}\text { Combined } \\
\text { examination } \\
\text { s }\end{array}$ & $\begin{array}{l}\text { Mid-semester } \\
\text { examination }\end{array}$ & $\begin{array}{l}\text { Final } \\
\text { examinatio } \\
\text { n }\end{array}$ & $\begin{array}{l}\text { Assignme } \\
\text { nt }\end{array}$ \\
\hline \multirow{2}{*}{$\begin{array}{l}\text { Percentage } \\
\text { lecture } \\
\text { attendance }\end{array}$} & All & 0.3168 & 0.3147 & 0.3558 & 0.2796 & 0.3736 & 0.1998 \\
\hline & Passing & 0.4129 & 0.3557 & 0.4053 & 0.3093 & 0.4283 & 0.2137 \\
\hline \multirow{2}{*}{$\begin{array}{l}\text { Number of } \\
\text { lectures } \\
\text { recordings } \\
\text { accessed to } \geq \\
80 \%\end{array}$} & All & -0.4974 & -0.4808 & -0.4263 & -0.3391 & -0.4459 & -0.4532 \\
\hline & Passing & -0.2868 & -0.3381 & -0.2580 & -0.1844 & -0.2802 & -0.3743 \\
\hline \multirow{2}{*}{$\begin{array}{l}\text { For students } \\
\text { who accessed } \geq \\
1 \text { lecture, } \\
\text { number of } \\
\text { lectures } \\
\text { accessed to } \geq \\
80 \%\end{array}$} & All & -0.3913 & -0.3632 & $\begin{array}{l}-0.3600 \\
\end{array}$ & -0.2177 & -0.4066 & -0.3236 \\
\hline & Passing & -0.1153 & -0.1211 & -0.0702 & -0.0403 & -0.1395 & -0.1893 \\
\hline
\end{tabular}

\section{Lecture recording access}

Accessing lecture recordings on Blackboard was not undertaken routinely by the students in the pharmacology course. Thus, only 26 of the participating 39 students accessed any of the lecture recordings; the other 13 students did not. The number of recordings accessed by the 26 students was low: thus 12 of the students did not access any recordings to $\geq 80 \%$ completion, a further six only accessed one recording to $\geq 80 \%$ completion, and the maximum access was to seven recordings by one student. Reducing the criteria for accessing the lecture recordings to $\geq 60 \%$ completion did not change these findings to any major extent. Thus, 10 of the students did not accessing any recording to $\geq 60 \%$ completion, five only accessed one recording, and the maximum access was to 10 recordings by two students.

\section{Lecture recording access and academic outcomes}

The regression line analysis of overall mark against number of lectures accessed to $\geq 80 \%$ completion for all of the participating students showed a weak negative correlation (Figure 2) i.e. the more lectures accessed, the weaker the academic outcomes. Regression line analysis also showed negative correlations when undertaken for number of lectures accessed to $\geq 80 \%$ completion against grade, combined examinations, mid-semester examination, final examination, and assignment (Table 2). Repeating the regression line analysis for academic outcomes against number of lectures accessed to $\geq 60 \%$ completion also showed weak negative correlations (data not shown).

The figure of the regression line analysis (Figure 2) suggests that the results for academic outcomes against lecture recordings access may have been influences by the high number of students who accessed lecture recordings but did not access any to $\geq 80 \%$ or $\geq 60 \%$ completion 
i.e. no lectures accessed at this level. Thus, we did additional regression line analysis of the academic outcomes for the students, who accessed at least one lecture recording to $\geq 80 \%$ completion, against number of lectures accessed to $\geq 80 \%$, which had to be $\geq 1$ lecture. This further regression line analysis continued to show a weak negative correlation for grade, overall marks, combined examinations, final examination, and assignment, but not for the midsemester examination (Table 2). Removing the students who did not access at least one lecture recording to $\geq 80 \%$ completion reduced the strength of the negative correlation coefficients (Table 2). This regression line analysis still seems to be suggesting that the more lecture recordings accessed, the weaker the academic outcomes.

The most outlying point in the regression line analysis, between overall mark and number of lecture recordings accessed to $\geq 80 \%$ in Figure 2, which is indicated by the unfilled symbol in the figure, belonged to the student who accessed six lecture recordings, but failed the course. Repeating the regression line analysis for the passing students (i.e. removing the data for the failing student) showed that the one failing student had a major impact on the analysis. Thus, after removing the failed student, there was a reduced weak negative correlation between accessing lecture recordings $\geq 80 \%$ and the overall mark and assignment, and there was no longer any correlation between accessing lecture recording and grade or any of the examinations (Table 2). After removing the student who failed the course, there were also no correlations for student who accessed $\geq 1$ lectures and to $\geq 80 \%$ and academic outcomes (Table 2) or for academic outcomes against number of lectures access to $\geq 60 \%$ completion (data not shown).

\section{Discussion}

The main findings of this study were that firstly, even with access to lecture recordings, students who attend $\geq 50 \%$ of lectures have better overall academic outcomes than those that attend $<50 \%$ of lectures. Secondly, there was a negative relationship between accessing lecture recordings and lecture attendance, such that students who accessed more lecture recordings had poorer academic outcomes. Furthermore, when the one student who failed the course was removed from the analysis, there was no relationship between accessing lecture recording and academic outcomes. These findings were with students studying pharmacology, a biological science. As it is not feasible to relate my findings to all the individual studies of how lecture attendance affects academic outcomes, my discussion of the findings about how lecture attendance and lecture recordings affect academic outcomes has been limited to comparisons with previous studies for biological science students of this relationship.

\section{Lecture attendance and academic outcomes}

Our finding that, despite the availability of lecture recordings, lecture attendance is still associated with better academic outcomes is supported by some but not all previous studies of this. Thus, for students studying the biological sciences who had access to lecture recordings, the outcomes were better for attending students in some studies (Fernandes, Maley, \& Cruickshank, 2008; Soto \& Anand, 2009; Horton et al., 2012; Selvig, Holaday, Purkiss, \& Hortsch, 2014; Popovic et al., 2018; Doggrell, 2018; and for one in four courses studied by Davis, Hodgson, \& Macaulay, 2012) but not for other studies (Hidayat, Vansal, Kim, Sullivan, \& Dalbu, 2012; Azab et al., 2016; and for the other three courses studied by Davis et al., 2012). The reason for the discrepancy between studies of students studying the biological sciences is probably not related to entry scores, as Davis et al., who only showed a benefit in attending lectures in one of four courses, also showed there were no differences in entry scores in the four courses (2012). 
A possible reason for the discrepancy between studies of the relationship between lecture attendance and academic outcomes is that most of the studies of students studying the biological sciences (Fernandes et al., 2008; Horton et al., 2012; Davis et al., 2012; Hidayat et al., 2012; Selvig et al., 2014; Azab et al., 2016; Popovic et al., 2018) used self-reported recall/survey as the measure of attendance and, this may not be accurate enough to determine any small benefits in attending lectures versus not. The previous studies of students studying the biological sciences that used a more accurate measure of attendance than self-report i.e. sign-in (Soto \& Anand, 2009; Doggrell, 2018) showed a positive relationship between lecture attendance and academic outcomes. Our study showing a similar positive relationship between lecture attendance and academic outcomes also used sign-in rather than self-report as the measure of attendance. Another positive advantage our study has over all the previous studies with biological science students, is that we had a $100 \%$ participation rate, which higher than that observed in the previous studies, and must be a better reflection of the class than studies where participation was less.

A second possibility for the difference is that the quality of lecturing varies such that not all lecturers add value/understanding to what is available by accessing Powerpoints or lecture recordings. Thus, poor lecturing may reduce lecture attendance and distort any relationship between lecture attendance and academic outcomes. In a survey of students studying pharmacology and biochemistry, nearly half identified poor quality of lecturing as a factor determining their lecture attendance (Davis et al., 2012).

I undertook a review of the percentage of studies of biological science students showing a positive association between lecture attendance and academic outcomes in the absence and presence of lecture recordings, and this suggested that the availability of lecture recordings reduces the likelihood of there being a positive association between lecture attendance and academic outcomes. In the absence of reported availability of lecture recordings, a positive association was shown for $93 \%$ of courses (13 of 14 studies) versus one course $(7 \%)$ not showing an association. There were 13 studies showing a positive association (Hamen \& Kelland, 1994; Gatherer \& Manning, 1998; Brown, Graham, Money, \& Rakoczy, 1999; Grisé \& Kenney, 2003; Khan, Khattak, Mahsud, Ali, Khan, Saleem, \& Shah, 2003; Moore et al., 2003; Moore, 2006; Hamdi, 2006; Salamonson et al., 2009; BinSaeed et al., 2009; Jaykaran, Yadav, Chavda, \& Kantharia, 2011; Stegers-Jager, Cohen-Schotanus, \& Themmen, 2012; Demir, Tutuk, Dogan, Egeli, \& Turner, 2017), and the one study not showing a positive association was that of Cohall and Skeete, 2012.

In contrast, in the presence of lecture recordings, a positive association was shown in $58 \%$ of courses ( 7 of 12 courses) versus $42 \%$ of courses not showing a relationship between lecture attendance and academic outcomes. There were seven courses showing a positive association (Fernandes et al., 2008; Soto \& Anand, 2009; Horton et al., 2012; Selvig et al., 2014; Popovic et al., 2018; Doggrell, 2018; and for one in four courses studied by Davis et al., 2012) and five courses not showing an association (Hidayat et al., 2012; Azab et al., 2016; and three courses studied by Davis et al., 2012). However, a major limitation to this suggestion, is that the comparison is between studies reporting and not reporting the availability of lecture recordings, which may not correspond to studies of courses that have or do not have lecture recordings available.

Although this study shows an association between lecture attendance and academic outcomes, it is not known whether the better outcomes achieved by the students who attended $\geq 50 \%$ of lectures is caused by the higher attendance. Another possibility is that is that it is students with higher ability that attend more lectures, and this leads to better academic outcomes, rather than 
lecture attendance per se. If attending lectures equated to higher ability, all the academic outcomes would be greater for the students who attended more lectures, and this is not the case. Thus, the marks for the assignment were not significantly higher for the students who attended $\geq 50 \%$ of lectures.

Not all outcomes for the pharmacology course were improved by lecture attendance. Thus, there was no difference in the outcomes for the assignment between students who attended $\leq$ $50 \%$ and those students who attended $>50 \%$ of lectures. This is probably an expected finding, as the assignment in this course was not related to the lecture content, and thus, there was no obvious benefit from attending lectures. To my knowledge, there has only been one other study of biological science students that has specifically looked at the relationship between lecture attendance and assignment mark, and that study showed a positive relationship between lecture attendance and assignment mark for nursing students studying pharmacology (Doggrell, 2018). However, these was a major difference between this study, where the assignment was not related to lecture content, and the previous study, where the assignment was related to lecture content (Doggrell, 2018). Thus, it is possible that lecture attendance improves outcomes for assignments related to lecture content, but not when the assignment is not related to lecture content.

The individual academic outcome most positively associated with lecture attendance was the final exam where there was an 18-percentage points advantage for those that attended $>50 \%$ of lectures. In contrast, in the mid-semester exam, there was only a 9-percentage points advantage for attending $>50 \%$ of lectures, which was not significant. One possible explanation for this is that the benefits of attending lectures increases over the duration of the semester/course. As other studies of students of biological sciences have not compared academic outcomes in mid-semester and final examinations, this explanation needs further testing.

The benefits of attending lectures observed in the present study may seem to be relatively modest. For instance, the grade was 6.5 for those that attended $\geq 50 \%$ vs 5.5 for those that attended $<50 \%$ of lectures. However, as Grade Point Averages (GPAs) are a major factor in determining entry into graduate programs (medicine/dentistry) and postgraduate programs in Australia, these differences can be important to individual students.

\section{Lecture recording access and academic outcomes}

The present study showed that accessing lecture recordings was negatively associated with academic outcomes in a pharmacology course. This finding contrasts with one study that found no association in a medical science course (Leadbeater et al., 2013), and another study that found that for seven of eight courses undertaken by medical students, other than pharmacology, there was also no association (Franklin et al., 2011). The reason for this difference between these studies and my study is not known, but the number of students accessing lecture recordings was higher in the studies showing no association (Franklin et al 2011; Leadbeater et al., 2013) than the present study, and this may be a contributing factor.

A recent study has found a positive association between accessing lecture recordings and academic outcomes for nursing students studying a course containing anatomy, physiology and microbiology (Guy et al., 2018). In this study, the nursing students also had access to other online resources i.e. an interactive anatomy atlas and concept clips, and these other resources may have contributed to the positive association between the access to lecture recordings and academic outcomes (Guy et al., 2018). 
However, my finding of a negative association between access lecture recordings and academic outcomes is in keeping with two studies of students studying the biological sciences (medical students, McNulty et al., 2009; nursing students, Johnston et al., 2013) and is supported by other studies showing that when students used lecture recordings, instead of attending pharmacology lectures, there academic outcomes were lower (Fernandes et al., 2008; Franklin et al., 2011). As it seems unlikely that accessing lecture recordings per se has a detrimental effect on academic outcomes, authors have not given this as an explanation for the negative association.

Two of the previous studies have given no reason for this negative association between accessing lecture recordings and academic outcomes (McNulty et al., 2009; Franklin et al., 2011), and one has suggested that it may be due to inaccurate self-reporting of accessing lecture recordings (Fernandes et al., 2008). One study has suggested that the high access of lecture recordings represents 'cramming' by the weaker students and this is responsible for the negative association (Johnston et al., 2013). This is supported by a previous study showing that the lower achieving students in a faculty of health were accessing lecture recording more often than high achievers (Owston, Lupshenyuk, \& Wideman, 2011).

However, when the one student who failed the course was removed from the linear regression of overall mark versus number of lectures accessed, there was no relationship between accessing lecture recording and academic outcomes. To my knowledge, this is the first study to undertake this analysis with and without failing students. Thus, the previous studies of the relationship between accessing lecture recordings and academic outcomes have been surveys, which have not indicated whether any students who failed the course responded to the survey, and have not separated the failing student in their analysis (Fernandes et al., 2008; McNulty et al., 2009; Franklin et al., 2011; Owston et al., 2011; Johnston et al., 2013; Leadbeater et al., 2013; Guy et al., 2018). Because of this, it is not possible to compare my analysis without the failing student to previous studies directly. However, the finding that removing the failing students changed the association between accessing lecture recordings and academic outcomes from a negative to no association is in keeping with previous suggestions that weaker/low achieving students access lecture recordings more than higher achieving students to produce a negative association (Owston et al., 2011; Johnston et al., 2013).

There are some limitations to this study. Firstly, it is a relatively small study of one group of students studying pharmacology. We have limited our introduction and discussion to studies of biological students. Thus, our results are limited to the context of biological science students and may differ from those for students studying other disciplines. Secondly, we only have data on access to lecture recordings, we do not know how they were being used by the students during access. Thus, some students may have been accessing the recordings for study, whereas other students may have been accessing recordings while undertaking other tasks. However, it should be noted that this limitation is common to all studies reporting on accessing lecture recordings.

In conclusion, as this study shows better academic outcomes for those students that attend $\geq$ $50 \%$ of lectures than for those that attend $<50 \%$ of lectures, face-to-face lectures should be continued. As lecture recordings were accessed more by the students who subsequently had poorer outcomes, it is possible but unlikely that accessing lecture recordings is detrimental. Another possibility is that accessing lecture recordings may have improved the outcomes for individuals who would have had poorer outcomes without this access. 


\section{Acknowledgement}

Thanks to Dr Peter Molenaar, who was the course coordinator, and sole academic involved in the pharmacology teaching, for allowing me access to his students to undertake this study.

\section{References}

Azab, E., Saksena, Y., Alghanem, T., Bidle, J.B., Molgaard, K., Albright, S., \& Karimbux, N. (2016). Association among dental students' class lecture attendance, use of online resources, and performance. Journal of Dental Education, 80(4), 452-458.

BinSaeed, A.A., al-Otaibi, M.S., al-Ziyar, H.G., Babsail, A.A., \& Shaik, S.A. (2009). Association between student absenteeism at a medical college and their academic grades. Journal of the International Association of Medical Science Educator, 19(4).

Brown, B., Graham, C., Money, S., \& Rakoczy, M. (1999). Absenteeism and grades in a nursing curriculum. Michigan Community College Journal: Research \& Practice, 5(2), 81-84.

Cohall, D.M., \& Skeete, D. (2012). The impact of an attendance policy on the academic performance of year medical students taking the Fundamentals of Disease and Treatment course. Caribbean Teaching Scholar, 2(2), 115-123.

Credé, M., Roch, S.G., \& Kieszczynka, U.M. (2010). Class attendance in college: A meta-analytic review of the association of class attendance with grades and student characteristics. Review of Educational Research, 80, 272 doi: 10.3202/0034654310362998

Davis, E.A., Hodgson, Y., \& Macaulay, J.O. (2012). Engagement of students with lectures in biochemistry and pharmacology. Biochemistry and Molecular Biology Education, 40(5), 300-309. doi: 10.1007/s00125-0174538-2

Demir, E.A., Tutuk, O., Dogan, H., Egeli, D., \& Tumer, C. (2017). Lecture attendance improves success in medical physiology. Advances in Physiology Education, 41(4), 599-603. doi: 10.1152/advan.00119.2017

Doggrell, S.A. (2018). Does attending lectures matter when lecture recordings are available? Results for a preliminary study comparing attending and non-attending nursing students in bioscience and pharmacology. International Journal of Innovation in Science and Mathematics Education, 27(7), 1-10.

Fernandes, L., Maley, M., \& Cruickshank, C. (2008). The impact of online lecture recordings on learning outcomes in Pharmacology. Journal of the International Association of Medical Science Educator, 18(2).

Franklin, D.S., Gibson, J.W., Samuel, J.C., Teeter, W.A., \& Clarkson. C.W. (2011). Use of lecture recordings in medical education. Medical Science Educator, 1, 21-29.

Gatherer, D., \& Manning, C.R. (1998). Correlation of examination performance with lecture attendance: A comparative study of first-year biological sciences undergraduates. Biochemical Education 26, 121-123. DOI: $10.1016 / \mathrm{S} 0307-4412(98) 00055-7$

Grisé, D.J., \& Kenney, A.M. (2003). Nonmajors' performance in biology - effects of student-based initiatives and class size. Journal of College Science Teaching, 33(2), 18-21. DOI: 10.2505/4/jcst03_0333_02_18

Guy, R., Byrne, B., \& Dobos, M. (2018). Optional anatomy and physiology e-learning resources: Student access, learning approaches, and academic outcomes. Advances in Physiology Education, 42, 43-49. Doi: 10.1152/advan.0007.2017

Hamdi, A. (2006). Effect of lecture absenteeism on pharmacology course performance in medical students. Journal of the International Association of Medical Science Educator, 16(1).

Hamen, C.S., \& Kelland, J.L. (1994). Attendance and grades in a human physiology course. American Journal of Physiology, 267(6 Pt 3), S105-108. DOI: 10.1152/advances.1994.267.6.S105

Hidayat, L., Vansal, S., Kim, E., Sullivan M., \& Dalbu, R. (2012). Pharmacy student absenteeism and academic performance. American Journal of Pharmaceutical Education, 76(1), 1-6. DOI: 10.5688/ajpe7618

Horton, D.M., Widerman, S.D., \& Saint, D.A. (2012). Assessment outcome is weakly correlated with lecture attendance: Influence of learning style and use of alternative materials. Advances in Physiology Education, 36(2), 108-115. doi: 10.1152/advan.00111.2011

Jaykaran, Yadav, P., Chavda, N., \& Kantharia, N.D. (2011). Factors associated with performance of second year student in pharmacology examinations. Journal of Pharmacology and Pharmacotherapy, 2(2), 123-125. doi: 10.4103/0976-500X.81911

Johnston, A.N.B., Massa, H., \& Burne, T.H.J. (2013). Digital lecture recording: A cautionary tale. Nurse Education in Practice, 13(1), 40-47. DOI 10.1016/j.nepr.2012.07.004

Khan, H.U., Khattak, A.M., Mahsud, I.U., Ali, S., Khan, M.H., Saleem, M., \& Shah, S.H. (2003). Impact of class attendance upon examination results of students in basic medical sciences. Journal of Ayub Medical College Abbotabad, 15(2), 56-58. 
Leadbeater, W., Shuttleworth, T., Couperthwaite, J., \& Nightingale, K.P. (2013). Evaluating the use and impact of lecture recording in undergraduates: Evidence for distinct approaches by different groups of students. Computers \& Education, 61,185-192. http://dx.doi.org/10.1016/j.compedu.2012.09.011

McKenzie, K., \& Schweitzer, R. (2001). Who succeeds at university? Factors predicting academic performance in first year Australian university students. Higher Education Research \& Development, 20(1)2, 21-33. DOI: 10.1080/07924360120043621

McNulty, J.A., Hoyt, A., Gruener, G., Chandrasekhar, A., Espiritu, B., Price Jr, R., \& Naheedy, R. (2009). An analysis of lecture video utilization in undergraduate medical education: associations with performance in the courses. BMC Medical Education, 9(6) doi:10.1186/1472-6920-9-6

Moore, R., Jensen, J., Hatch, H., Duranczyk, I., Staats, S., \& Koch, L. (2003). Showing up: The importance of class attendance for academic success in introductory science courses. The American Biology Teacher, 65(5), 325-329.

Moore, R. (2006). Helping students succeed in introductory biology classes: Does improving students' attendance also improve their grades? Bioscene, 29(3), 17-25.

Owston, R., Lupshenyuk, D., \& Wideman, H. (2011). Lecture capture in large undergraduate classes: Student perceptions and academic performance. The Internet and Higher Education, 14(4), 262-268. https://doi.org/10.1016/j.iheduc.2011.05.006

Popovic, N., Popovic, T., Dragovic, I.R., \& Cmiljanic, O. (2018). A Moodle-based blended learn solution for physiology education in Montenegro: A case study. Advances in Physiology Education, 42(1), 111-117. DOI:10.1152/advan.00155.2017

Salamonson, Y., Andrew, S., \& Everett, B. (2009). Academic engagement and disengagement as predictors of performance in pathophysiology among nursing students. Contemporary Nurse, 32(1-2), 123-132.

Selvig, D., Holaday, L.W., Purkiss, J., \& Hortsch, M. (2015). Correlating students' educational background, study habits, and resource usage with learning success in medical histology. Anatomical Science Education, 8(1), 1-11. DOI 10.1002/ASE.1449

Soto, J.G., \& Anand, S. (2009). Factors influencing academic performance of students enrolled in a lower division cell biology core course. Journal of the Scholarship of Teaching and Learning, 9(1), 64-80.

Stegers-Jager, K.M., Cohen-Schotanus, J., \& Themmen, A.P.N. (2012). Motivation, learning strategies, participation and medical school performance. Medical Education, 46, 678-688. doi: 10.1111/j.13652923.2012.0428.x

Traphagan, T., Kucsera, J.V., \& Kyoko, K. (2010). Impact of class lecture webcasting on attendance and learning. Educational Technology Research and Development, 58, 19-37.

Weiling, M.B., \& Hofman, W.H.A. (2010). The impact of online video lecture recordings and automated feedback on student performance. Computers \& Education, 54(4), 992-998. Doi:10.1016/j.compedu.2009.10.002

Williams, A., Birch, E., \& Hancock, P. (2012). The impact of online lecture performance on student performance. Australasian Journal of Educational Technology, 28(2), 199-213. 